\title{
ASPECTOS ECOLÓGICOS DA VEGETAÇÃO RUPESTRE DA SERRA DOS CARAJÁS, ESTADO DO PARÁ, BRASIL.'
}

\author{
Manoela F. F. da SILVA ${ }^{2}$, Ricardo de S. SECCO², Maria da Graça A. LOBO ${ }^{2}$
}

\begin{abstract}
RESUMO - São fornecidos aspectos ecológicos gerais da vegetação "rupestre" da Serra dos Carajás, envolvendo informaçōes sobre composição florística, associação solo/planta, fauna/planta e distribuição geográfica das espécies. Nesta vegetação foi registrado um total de 232 espécies, a maioria ervas. distribuídas em 145 gêneros e 58 familias botânicas. As duas familias mais bem representadas foram Gramineae e Leguminosae, seguidas de Cyperaceae, Myrtaceae, Rubiaceae, Malpighiaceae, Euphorbiaceae e Compositae. Algumas famílias apresentam espécies arbóreas esporadicamente representadas em "capões de árvores" ou isoladas como Anacir diaceae, Rutaceae. Sapotaceae e Vochysiaceae. Há familias de ocorrência restrita em locais onde há actimulo de água, como Begoniaceae, Burmaniaceae, Eriocaulaceae, Gentianaceae, etc. E finalmente aquelas famílias de ocorrência apenas ocasional, como Acanthaceae, Annonaceae. Chrysobalanaceae. Palmae, Sterculiaceae, etc. Parece que os polinizadores mais comumente encontrados na vegetação rupestre são as abelhas. Há também outros animais ali associados à biologia das plantas como meliponídeos, tabanídeos, répteis e pássaros. Além de apresentar uma insignificante camada lodosa, associada a musgos e líquens o solo onde se assenta a vegetação "rupestre" apresenta uma grande quantidade de ninhos de cupins, na transição entre as estações seca e chuvosa. A necessidade de preservação da área estudada justifica-se pela presença de inúmeras espécies endêmicas (ex. Ipomoea cavalcantei Austin), espécies novas para a ciência (ex. Erytroxylum nelson-rosae Plowman), espécies medicinais (ex. Pilocanus microphylus Stapt. ex. Wardleworth) e espécies ornamentais (ex. Vellozia glochidea Pohl), todas associadas a uma fauna e a um tipo de solo que ainda carecem de pesquisas mais aprofundadas para melhor conhecê-los.
\end{abstract}

Palavra-chave: Savana Tropical, Fitossociologia, Fitogeografia, Vegetação rupestre, Amazônia.

Ecological Aspects of the Tropical Scrub Vegetation on Rocky Outcrops of the Serra dos Carajás, State of Pará, Brazil.

ABSTRACT - General ecological aspects of the tropical scrub vegetation on rocky outcrops ("campo rupestre") of the Serra dos Carajás, Pará, Brazil, are discussed, with information on its floral composition, the associations of plant species with soil type and animals, and the geographical distributions of component plant species. The plant community studied is composed of a total of 232 species, mostly herbaceous, belonging to 145 genera and 58 plant families. The two most common families were Gramineae and Leguminosae, followed by Cyperaceae, Myrtaceae, Rubiaceae, Malpighiaceae, Euphorbiaceae and Compositae. Some families have arboreal species sporadically found in forest islands ("capões de árvores") or as isolated trees, such as Anacardiaceae, Rutaceae, Sapotaceae and Vochysiaceae. Some families are restricted in occurrence to areas where water accumulates, such as Begoniaceae, Burmaniaceae, Eriocaulaceae, Gentianaceae, etc. Some families occur only rarely, such as Acanthaceae, Annonaceae, Chrysobalanaceae, Palmae, Sterculiaceae, etc. It appears that the most common pollinators in the area are bees. Other animals are also associated with the plants of this community, such as tabanid horseflies, reptiles and birds. The soil on which this plant community is based, besides having a very thin organic layer associated with mosses and lichens, has a large number of termite nests, in the transition from dry to rainy season. The biological preservation of the study area is justified by the large number of endemic species (for example, Ipomoea cavalcantei Austin), new species (for example, Erytroxylum nelson-rosae Plowman), species with potential as sources of drugs (for example, Pilocarpus microphylus Stapf. ex. Wardleworth), and ornamental plant species (for example, Vellozia glochidea Pohl), all of which belong to this community whose associated animals and soil types are yet so poorly researched.

Key-Words: Tropical savannas, Phytosociology, Phytogeography, Mining, Amazon, Brazil.

Trabalho realizado com auxilio CNPq - Processo no 500380/90-2/ZO/DF e recursos do convênio CVRD/ MPEG, contrato 16/83.

2 CNPq/Museu Paraense Emilio Goeldi, Dept ${ }^{\circ}$ Botânica, Cx. Postal 399, 66.040-170, Belém, Pa, Brasil

ACTA AMAZONICA 26(1/2): 17-44. 1996. 


\section{INTRODUÇÃO}

A Serra dos Carajás é uma imensa província mineral, situada no interior da Amazônia brasileira e coberta quase em sua totalidade por vegetação natural. Até por volta de 1967, quando foram descobertas as primeiras jazidas de minério em Carajás, eram poucas as informações sobre a vegetação daquela região.

No início do século presente, a Serra dos Carajás era praticamente desconhecida, não havia sequer recebido sua denominação formal. Os primeiros colonizadores se estabeleceram na foz do rio Itacaiúnas, por volta de 1895, onde é hoje a cidade de Marabá. As tribos Carajás-mirins e Carajás-pacus localizavam-se nas vizinhanças da serra. A população daquela região era confinada aos vales dos grandes rios e vivia do extrativismo de caucho e castanha. A invasão da floresta à procura destes produtos provocou a expulsão e extinção dos indígenas, restando hoje apenas a aldeia dos Chicrins nas proximidades de Carajás, às margens do rio Cateto.

Com o programa de prospecção geológica de Carajás, iniciado por volta de 1966-1967, foram descobertas grandes jazidas minerais que permitem considerar aquela região como a principal província mineral do mundo.

O corpo de minério de ferro é recoberto por uma camada de "canga hematítica", que representa um grau de intemperização do minério. Sobre a canga cresce uma vegetação baixa, com poucos indivíduos de porte arbóreo, tomando um aspecto de clareira, bem destacada da floresta tropical circunvizinha. Estas clareiras configuram-se como um tipo especial de vegetação, com um estrato graminoso bem evidente e a presença marcante de outras espécies herbáceas. O aspecto de clareira desta vegetação foi importante desde o início das pesquisas geológicas; ainda na fase de fotointerpretação serviu como indicador para as descobertas de minério da região.

A primeira referência à vegetação de "canga" de Carajás surgiu em 1933. descrita pelo engenheiro Luis Flores de Moraes Rêgo, referindo-se ao alto Itacaiúnas como: "morros de topo plano onde se encontram campos gerais". O primeiro estudo sistemático da Serra dos Carajás foi um reconhecimento aéreo fitofisionômico feito pelo geógrafo Luis de Castro Soares, em 1951-1952 de São Félix do Xingu a Marabá; neste foi observado a existência de formações não florestais, correspondentes às clareiras que hoje são reconhecidas como indicadoras de jazidas de ferro (SILVA, 1989).

Ainda hoje é controvertida a terminologia utilizada para denominar o tipo de vegetação que cresce diretamente sobre o afloramento rochoso de Carajás, a "canga hematítica". Tem sido usado genericamente o termo "vegetação de canga" (por exemplo, SECCO \& MESQUITA 1983). SILVA et al. (1986), SECCO \& LOBO (1988) e SILVA \& ROSA (1990) usaram o termo "campo rupestre". PORTO \& SILVA (1987) usaram o termo "vegetação metalófila" para o tipo de cobertura vegetal que cresce sobre afloramento de minério em Carajás e Minas Gerais.

Esta comunidade vegetal tem fronteiras geográficas bem definidas, limitando-se às áreas de canga hematítica, 
constituindo-se um verdadeiro "enclave", circundado por floresta tropical.

Uma vez que este tipo de vegetação cresce diretamente sobre as jazidas minerais de ferro, supõe-se que haja influência da mineralização sobre a mesma e talvez o fator seletivo mais crítico seja a alta concentração de metais pesados, acrescido de outros como a pobreza de nutrientes e a baixá capacidade de retenção de água (SILVA 1989). Estes fatores parecem exercer pressão ambiental, provocando uma seleção natural muito rigorosa.

Com o objetivo de estudar os recursos biológicos, hidrológicos, pedológicos e arqueológicos de Carajás sob influência de exploração mineral, o Museu Paraense Emílio Goeldi conduziu um programa de pesquisas naquela região, no período de 1983 a 1987.

Os resultados dos levantamentos florísticos estão publicados nos seguintes trabalhos: SECCO \& MESQUITA (1983), SILVA (1988), SILVA (1989), SILVA \& ROSA (1989), SILVA \& ROSA (1990), SILVA et al. (1986), SECCO \& LOBO (1988) e PORTO \& SILVA (1987), entre outros.

Quanto aos resultados aqui apresentados sobre polinização, dispersão e associação planta/solo e cupins, são ainda preliminares e estão sendo divulgados com a finalidade de estimular estudos dessa natureza na serra dos Carajás e, principalmente, porque trabalhos sobre tipos de vegetação da Amazônia raramente abordam estes aspectos da biologia das plantas.

\section{MATERIAL E MÉTODOS}

Para o estudo da vegetação que cresce diretamente sobre a "canga de ferro" em Carajás procedeu-se levantamentos qualitativos exaustivos ao longo de 5 anos, em diferentes estações. Estes levantamentos foram feitos à base de coletas gerais em todas as áreas de "canga" e o material coletado pode ser visto na Tabela 1.

O procedimento de campo foi o seguinte:

Identificação botânica provisória de família, gênero e espécie, se possível, e nome vulgar.

Coleta de amostra do material botânico, o mais completo possível, para análise e devida identificação no herbário.

Anotação de dados complementares como: aspectos fisionômicos: hábito de crescimento; tipo de caule, raiz e folhas; xilopódios, xeromorfismo, suculência, esclerofilia, etc.

No laboratório foi realizada a identificação botânica por comparação com o material herborizado e com o auxílio de monografias e chaves analíticas, após o exame em microscópio óptico. Com relação aos grupos de difícil identificação, o material herborizado foi encaminhado para os especialistas dos mesmos.

As observações sobre polinização e dispersão, bem como aquelas sobre associação planta/solo e cupins foram feitas em áreas de vegetação "rupestre" (canga) da serra dos Carajás (serra Norte e serra Sul), durante 5 excursões ali realizadas: duas em estação chuvosa ( fevereiro e abril ) uma em período intermediário entre estações 
Tabela 1. Relação das espécies registradas sobre canga hematítica (vegetação rupestre) na Serra Norte - Carajás (PA).

Familial ESPÉCIE NOME E NÚMERO DO COLETOR PTERIDÓFITAS

Polypodiaceae

* Poypodium triseriale Sw.

M.F.F. da Silva et al., 1672

ANGIOSPERMAS/MONOCOTILEDÓNEAS

Araceae

* Anthurium solitarium (Vell.) Schott.

* Philodendron sp.

Bromeliaceae

* Ananas ananassoides (Baker) L.B. Smith

* Dickia duckei L.B. Smith

* Pitcairnia lanuginosa R. \& P.

* P. cf. torresiana L.B. Smith

Burmanniaceae

* Burmannia cf. bicolor Mart.

Cyperaceae

* Bulbostylis caespitosa Hochst

* Cyperus haspan L.

* Cyperus sp.

* C. compressus L.

* Eleocharis capitata Miq.

* E. interstincta R. Br.

* E. mutata R. et Sch.

* Rhynchospora sp.

* Rhynchospora barbata (Vahl) Kunth

* R. corimbosa (L.) Britl.

* R. cf. tenerrima Boeck

* R. tenuis ssp. riparia T. Koyama

* R. cyperoides (Sw.) Mart.

* R. globosa (H.B.K.) P. et S.

* Scleria foliosa Wright

Dioscoreaceae

* Dioscorea sp.

* Dioscorea huberi R. Knuth

Eriocaulaceae

* Paepalanthus cf. fasciculatus var. icanensis Herzog

* Syngonanthus gracilis (Koern.) Ruhi.

* S. caulescens var. angustifolius Moidenke

* Eriocaulon affaquatile Koern.

Gramineae

* Axonopus cf. leptostachyus (Flugge) Hitch.

* Eragrostis aff. maypurensis (H.B.K.) Steud.

* Ichnanthus acuminatus Sw.

* I. tenuis (Press.) Hitchc.

* I. axillaris (Nees) Hit.

* I. breviscrobs Doell.

* I. calvescens Doell.

* Manisuris sp.

* Mesosetum sp. (l)

* Mesosetum sp. (II)

M.F.F. da Silva et al., 1632 M.F.F. da Silva et al., 1669

M.F.F. da Silva et al., 1663c M.F.F. da Silva et al., 1657 M.F.F. da Silva et al., 1320 M.F.F. da Silva et al., 1676a

M.F.F. da Silva et al., 1642

M.F.F. da Silva et al., 2460 M.F.F. da Silva et al., 1706 M.F.F. da Silva et al., 1687 M.F.F. da Silva et al., 1703 M.F.F. da Silva et al., 1877 M.F.F. da Silva et al., 1879 M.F.F. da Silva et al., 1878 M.F.F. da Silva et al., 1674 M.F.F. da Silva et al., 1698 M.F.F. da Silva et al., 1646 M.F.F. da Silva et al., 1704 M.F.F. da Silva et al., 1699 M.F.F. da Silva et al., 1696 M.F.F. da Silva et al., 1672 M.F.F. da Silva et al., 1697

M.F.F. da Silva et al., 1650 M.F.F. da Silva et al., 1730

M.F.F. da Silva et al., 1695 M.F.F. da Silva et al., 1689 M.F.F. da Silva et al., 1861 M.F.F. da Silva et al., 1868

M.F.F. da Silva et al., 1623 R.S. Secco et al., 212 M.F.F. da Silva et al., $1671 \mathrm{~b}$ M.F.F. da Silva et al., 1846 M.F.F. da Silva et al., 1609 M.F.F. da Silva et al., 2461 N.A. Rosa et al., 4682 M.F.F. da Silva et al., 1840 M.F.F. da Silva et al., 1700a N.A. Rosa et al., 4685 


\section{Cont. Tabela 1}

* Panicum parvifolium Lam.

* Paspalum aspidiotes Trin.

* P. carinatum Flugg.

* P. multicaule Poir.

* P. parviflorum Rohde

* P. virgatum $L$.

* Paspalum sp. (I)

* Paspalum sp. (II)

* Sporobolus sp.

* Streptostachys asperifolia Desv.

* Thrasya longiligulata

* Trachypogon macroglossus Trin.

* T. plumosus (H. \& B.) Nees

* Trachypogon sp.

Marantaceae

* Maranta sp.

Orchidaceae

* Catasetum discolor Lindl.

* Epidendrum nocturnum Jacq.

* E. purpurascens Focke

* Habenaria cf. lasioglossa Cogn.

* Oncidium baueri Lindi.

* Sobralia liliastrum Lindl.

Palmae

* Oenocarpus distichus Martius

Velloziaceae

* Vellozia glochidea Pohl.

* Vellozia sp.

Xyridaceae

* Xyris aff. longiceps Malme

* X. laxifolia Mart.

\section{ANGIOSPERMAE/DICOTILEDÔNEAE}

Acanthaceae

* Ruellia sp.

Anacardiaceae

* Anacardium microcarpum Ducke

* Tapirira guianensis Aubl.

Annonaceae

* Guatteria poeppigiana Mart.

* Xylopia sp.

Apocynaceae

* Mandevilla hirsuta (A. Rich.) K. Sch.

* M. scabra (Roem \& Schult.) K. Sch.

* Odontadenia cf. geminata (R. et Sch.) M. Arg.

* Forsteronia sp.

Begoniaceae

* Begonia guyanensis A. DC.

* B. humilis A. DC.

Bignoniaceae

* Anemopaegma aff. scabriuscula Mart. ex DC.
M.F.F. da Silva et al., 1678

M.F.F. da Silva et al., 1600

M.F.F. da Silva et al., 1659

N.A. Rosa et al., 4686

M.F.F. da Silva et al., 1829

N.A. Rosa et al., 4684

N.A. Rosa et al., 4691

A.S.L. Silva et al., 1817

M.F.F. da Silva et al., 1499

M.F.F. da Silva et al., 2462

M.F.F. da Silva et al., 1844

M.F.F. da Silva et al, 1622

M.F.F. da Silva et al., 2463

M.F.F. da Silva et al., 1853

M.F.F. da Silva et al., 2496

M.F.F. da Silva et al., 1379

M.F.F. da Silva et al., 1483

M.F.F. da Silva et al., 1675

M.F.F. da Silva et al., 1671a

R.S. Secco et al., 341

M.F.F. da Silva et al., 1638

M.F.F. da Silva et al., 2464

M.F.F. da Silva et al., 1661

N.A. Rosa et al., 4728

M.F.F. da Silva et al., 1692

M.F.F. da Silva et al., 1707

M.F.F. da Silva, 1393

M.F.F. da Silva, 1333

M.F.F. da Silva et al., 2465

M.F.F. da Silva et al., 1611

M.F.F. da Silva et al., 2466

M.F.F. da Silva et al., 1647

M.F.F. da Silva et al., 1790

R.S. Secco et al., 167

M.F.F. da Silva et al., 1791

M.F.F. da Silva et al., 1646

M.F.F. da Silva et al., 1481

M.F.F. da Silva et al., 1664 
* A. pabstii A. Gentry

- Arrabidaea sp.

* A. cinnamomea (DC) Sandw.

* Jacaranda aff. praetermissa Sandw

* Leucocalantha aromatica Barb. Rodr.

- Phryganocydia corymbosa (Vent) Bur. el .K. Sch.

* Pleonotoma jasminifolia (H.B.K.) Miers

Cactaceae

* Pilocereus sp.

* Phyllocactus phylanthus (L.) Link

Chrysobalanaceae

* Licania egleri Prance

* Acioa sp.

Compositae

* Ichthyothere terminalis Blake

* Lomatozoma sp.

* Melampodium sp.

* Riencourtia glomerata Cass.

* Vernonia muricata DC.

* $V$. paraensis H. Robson

* $V$. remotiflora Rich.

Convolvulaceae

* Evolvulus sp.

* Ipomoea carajasensis D. Austin

- 1. cavalcantei D. Austin

* I. marabaensis D. Austin \& Secco

* Ipomoea sp.

Erythroxylaceae

* Erythroxylum ligustrinum var. carajasense Plowman

* E. nelson-rosae Plowman

* E. suberosum St. Hil. Sens. Lat.

* E. cf. citrifolium A. St. Hil.

Euphorbiaceae

- Actinostemon schomburgkii Hochr

* Alchornea discolor Poeppig

* Aparisthmium cordatum (Juss.) Baill.

* Croton aff. agrophilus Muell. Arg.

* $C$ ferrugineus H.B.K.

* C. jatropha Muell. Arg.

* C. tomentosus Link.

* Maprounea guianensis Aubl.

- Sapium marginatum Muell. Arg.

Flacourtiaceae

* Casearia arborea (L.C. Rich.) Urban

Gentianaceae

* Schuitesia pohliana Pr.

* Limnanthemum humboldtianum Griseb.

Hippocrateaceae

* Hippocratea cf. volubilis L.
M.F.F. da Silva et al., 1777

M.F.F. da Silva, 1383

M.F.F da Silva et al., 1780

R.S. Secco et al., 146

M.F.F. da Silva et al., 2467

M.F.F. da Silva et al., 1770

M.F.F. da Silva et al., 1674

M.F.F. da Silva et al., 1676

M.F.F. da Silva et al., 1797

M.F.F. da Silva et al., 2468

M.F.F. da Silva et al., 1795

M.F.F. da Silva et al., 1763

M.F.F. da Silva et al., 1479

M.F.F. da Silva et al., 1317

M.F.F. da Silva et al., 1650

M.F.F. da Silva., 1624

N.A. Rosa et al., 4747

M.F.F. da Silva et al., 2469

M.F.F. da Silva et al., 1810

M.F.F. da Silva et al., 1637

M.F.F. da Silva et al., 1631

N.A. Rosa et al., 4675

M.F.F. da Silva et al., 1634

N.A. Rosa et al., 5014

M.F.F. da Silva et al., 1736

M.F.F. da Silva et al., 1687

M.F.F. da Silva et al., 1691

M.F.F. da Silva et al., 1748

M.F.F. da Silva et al., 1648

R.S. Secco et al., 181

M.F.F. da Silva et al., 1635

M.F.F. da Silva et al., 1856

M.F.F. da Silva et al., 1874

M.F.F. da Silva et al., 1630

M.F.F. da Silva et al, 2470

M.F.F. da Silva et al, 1663a

M.F.F. da Silva et al., 2471

M.F.F. da Silva et al., 1334

M.F.F. da Silva et al., 1762

M.F.F. da Silva et al., 2472 
Humiriaceae

* Saccoglottis mattogrossensis Malme.

Lauraceae

* Cassytha americana Nees

* Mezilaurus itauba (Meissn.) Taubert ex Mez.

Leguminosae

Leguminosae Caesalpinioideae

- Bauhinia pulchella Bentham

* Cassia calycioides DC.

* Cassia sp.

* Chamaecrista flexuosa (L.) Greene

* Chamaecrista sp.

- C. bahia (Irwin) Barneby

* C. cf. trichopoda (Bentham) Britton \& Rose ex.

Britton \& Killip

* Sclerolobium paniculatum Vog.

Leguminosae Mimosoideae

* Mimosa acutistipula var. ferrea Barneby

* $M$. desmodioides var. carajarum Barneby

* $M$. somnians var. viscida Barneby

* Mimosa sp.

* Parkia platycephala Benth.

Leguminosae Papilionoidae

* Abrus fruticulocus Wall.

- Aeschynomene sp.

* Camptosema nobilis Lind.

* Centrosema pubescens Bentham

* C. carajasensis P. Cavalcante

* Derris cf. floribunda (Benth.) Ducke

* Dioclea cf. crenata Maxwell

* Periandra mediterranea (Vell.) Taubert

* Phaseolus cf. linearis H.B.K.

*Phaseolus sp.

* Stylosanthes humilis H.B.K.

Lentibulariaceae

- Utricularia nervosa G. Web.

* U. subulata L.

* Utricularia sp.

* U. obtusa Sw.

Loranthaceae

* Phthirusa paniculata (H.B.K.) Macbr.

Lythraceae

* Cuphea annulata Koelme

* C. tenella Hook. \& Arn.

*C. tenuissima Koelme

Malpighiaceae

* Banisteriopsis malifolia var. apressa Gates

* B. cf. stellaris (Gris.) Gates

* Brysonima coriacea (Sw.) Knuth.

* B. spicata (Cav.) H.B.K.
M.F.F. da Silva et al., 2473

M.F.F. da Silva et al., 1670

A.S.L. Silva et al., 1830

M.F.F. da Silva et al., 1627

R.S. Secco et al., 298

M.F.F. da Silva, 1337

N.A. Rosa et al., 4679

M.F.F. da Silva et al., 1872

M.F.F. da Silva et al., 1630

M.F.F. da Silva et al., 1627

M.F.F. da Silva et al., 1965

M.F.F. da Silva et al., 1629

M.F.F. da Silva et al., 1632

M.F.F. da Silva et al., 1658

M.F.F. da Silva et al., 1752

N.A. Rosa et al., 4582

M.F.F. da Silva et al., 1756

M.F.F. da Silva et al., 1678

M.F.F. da Silva et al., 1841

N.A. Rosa et al., 4578

A.S.L. Silva et al., 1848

M.F.F. da Silva et al., 2474

M.F.F. da Silva et al., 1636

M.F.F. da Silva et al., 1625

M.F.F. da Silva et al., 2475

M.F.F. da Silva et al., 1624

M.F.F.da Silva et al., 1498

M.F.F. da Silva et al., 1838

M.F.F. da Silva et al., 1643

A.S.L. Silva et al., 1801

M.F.F. da Silva et al 1841

M.F.F. da Silva et al., 1649

M.F.F. da Silva et al., 1628

M.F.F. da Silva et al., 1662

M.F.F. da Silva et al., 1749

M.F.F. da Silva et al., 1664a

M.F.F. da Silva et al., 2476

M.F.F. da Silva et al., 1663

M.F.F. da Silva et al., 2477 
Cont. Tabela 1

* Coleostachys genipifolia Aorjuss

* Mascagnia sp.

* Tetrapterys mucronata Cav.

* T. cf. benthamiana Griseb.

Malvaceae

* Sida sp.

Marcgraviaceae

* Norantea goyazensis Cambess.

Melastomataceae

* Aciotis sp.

* Appendicularia sp.

* Miconia cf. heliotropoides Triana

* $M$. alborufescens Naudim

* Pterolepis trichotoma Cogn.

* Tibouchina aspera Aubl.

* T. cf. spruceana Cogn.

Menispermaceae

* Cissampelos andromorpha DC.

* Sciadotenia cf. paraensis (Eihl.) Dicl. Myrtaceae

* Campomanesia sp.

* Eugenia flavescens DC.

* E. punicifolia (H.B.K.) DC.

* Eugenia sp.

* Myrcia sp.

* M. atramentifera B. Rodr.

* $M$. cf. falax (Rich.) DC.

* M. cf. marowyyensis

* $M$. cf. splendens (Sw.) DC.

* M. multiflora (L.) DC.

* $M$. silvatica (Mey) DC.

Nyctaginaceae

* Neea sp

* Guapira sp.

Ochnaceae

* Ouratea castanaefolia (DC.) Engl.

* O. paraensis Hub.

* Sauvagesia tenella Lam.

Olacaceae

* Heisteria ovata Benth.

Piperaceae

* Peperomia uaupensis Yuncher

* Piper arboreum Aubl.

* Piper

* Piper belterraense Yuncker

* Piper jemeraranum (Miq.) DC.

* Piper krukoffii Yuncker

* Piper rhombifolium Yuncker

* Peperomia mauplusis Yuncker
M.F.F. da Silva et al., 1744

M.F.F. da Silva et al., 1667

M.F.F. da Silva et al., 1639

M.F.F. da Silva et al., 1745

M.F.F. da Silva et a/., 1828

M.F.F. da Silva et al., 1609

M.F.F. da Silva et al., 1666b M.F.F. da Silva et al., 1655 M.F.F. da Silva et al., 1654 M.F.F. da Silva et al. 1826 M.F.F. da Silva et al., 2478 M.F.F. da Silva et al., 1660 M.F.F. da Silva et al., 1807

M.F.F. da Silva et al., 2479 M.F.F. da Silva. 1773

M.F.F. da Silva et al., 2480 M.F.F. da Silva et al., 1683 M.F.F. da Silva et al., 1653 M.F.F. da Silva et al., 1757 M.F.F. da silva et al., 1814 M.F.F. da Silva et al., 1816 M.F.F. da Silva et al., 2481 M.F.F. da Silva et al., 1812 M.F.F. da Silva et al., 1813 M.F.F. da Silva et al., 1670 M.F.F. da Silva et al., 1815

M.F.F. da Silva et al., 2482 M.F.F. da Silva et al., 1788

M.F.F. da Silva et al., 1677 M.F.F. da Silva et al., 2483 M.F.F. da Silva, 1339

M.F.F. da Silva et al., 1667a

M.F.F. da Silva et al., 1676 M.F.F. da Silva et al., 1781 M.F.F. da Silva et al., 1782 M.F.F. da Silva et al., 1785 M.F.F. da Silva et al., 1786 M.F.F. da Silva et al., 1783 M.F.F. da Silva et al., 1787 M.F.F. da Silva et al, 1784 
Polygalaceae

* Polygala variabilis H.B.K.

* P. spectabilis DC.

Polygonaceae

* Coccoloba latifolia Lam.

Proteaceae

* Roupala montana Aubl.

Rubiaceae

* Alibertia longiflora R. Sch.

- Borreria latifolia (Aubl.) R. Sch.

* B. tenera DC.

* Chomelia cf. pohliana Muelf. Arg.

* Mitracarpus sp.

* Perama carajaensis Kirbride

* Psychotria barbiflora DC.

" Psychotria sp.

* Richardia sp. (I)

* Richardia sp. (II)

Rutaceae

* Pilocarpus microphyllus Stapf ex Wardleworth

- Pilocarpus sp.

Sapindaceae

* Allophylus sp.

* Cupania rubiginosa Radlk.

* Matayba arborescens (Aubl.) Radlk.

* M. melecans Radlk.

- Paullinia spicata Radlk.

* Serjania sp.

Sapotaceae

* Franchetella parviflora Pires

* Pouteria parviflora Radlk

* P. ovata A.C. Smith

Smilacaceae

* Smilax campestris Griseb.

Solanaceae

* Solanum crinitum Lam.

* Solanum sp.

Sterculiaceae

* Melochia villosa (Mill.) Fawc. \& Rendle

Turneraceae

* Piriqueta cf. cistoides (L.) Griseb.

* Turnera glaziovii Urb.

Verbenaceae

* Lippia grandis Schau.

* Vitex triflora Vahl

Vitaceae

" Cissus erosa L.C. Rich.

* C. sulcicaulis Baker

Vochysiaceae

* Callisthene minor Mart.

* Indeterminada
M.F.F. da Silva et al., 2484

M.F.F da Silva et al., 1792

M.F.F. da Silva et al., 2485

M.F.F. da Silva et al., 2486

M.F.F. da Silva et al., 1651

M.F.F. da Silva et al., 2487

R.S. Secco et al., 445

M.F.F. da Silva et al., 1770

M.F.F. da Silva et al., 1665

M.F.F. da Silva et al., 1601

M.F.F. da Silva et al., 1769

R.S. Secco et al., 240

M.F.F. da Silva et al., 1666a

A.S.L. da Silva et al., 1758

M.F.F. da Silva et al., 1669a

M.F.F. da Silva et al., 2488

M.F.F. da Silva et al., 1682

M.F.F. da Silva et al., 1713

M.F.F. da Silva et al., 2489

M.F.F. da Silva et al., 1681

M.F.F. da Silva et al., 2490

M.F.F. da Silva et al., 2491

M.F.F. da Silva et al., 1712

M.F.F. da Silva et al., 1678

M.F.F. da Silva et al., 1740

M.F.F. da Silva et al., 2492

M.F.F. da Silva et al., 1644

M.F.F. da Silva et al., 2493

M.F.F. da Silva et al., 1693

M.F.F. da Silva et al., 2494

M.F.F. da Silva et al., 1654

M.F.F. da Silva et al., 1643

M.F.F. da Silva et al., 1728

M.F.F. da Silva et al., 1645

M.F.F. da Silva et al., 1729

M.F.F. da Silva et al., 1625

M.F.F. da Silva et al.,2495 
seca e chuvosa (junho), e duas em estação seca (agosto e outubro). especialemte nos morros N1, N2, N3, N4 e N5. Referidas observações foram feitas nas áreas como um todo, de modo aleatório, sem ter sido marcado nenhum local específico para realizá-las, e para isso utilizou-se binóculo Pentax $8 \times 40$. No caso dos insetos, estes foram coletados e trazidos em álcool para o Departamento de Zoologia (secção de Entomologia) do Museu Emílio Goeldi, onde foram identificados.

\section{Localização da Área Estudada}

O complexo Carajás localiza-se ao sul do Estado do Pará e norte do Estado de Goiás, na área de interferência das bacias dos rios Araguaia-Tocantins e Xingu, abrangendo uma superfície de 150.000 km2. A Serra dos Carajás propriamente dita corresponde à feição morfológica mais marcante, e está situada a $130 \mathrm{~km}$ a oeste de Marabá, no sul do Estado do Pará, entre os paralelos 5054' 6033'S e os meridianos 49053' 50034'WG. É banhada pelas bacias dos rios Itacaiúnas e Parauapebas (Fig. 1).

A principal área da Serra dos Carajás caracteriza-se por uma série de serras descontínuas, cujas principais elevações são: Serra Norte, Serra Sul e Serra Leste. A Serra Norte é formada por vários morros de minério de ferro com elevações de 600 a $800 \mathrm{~m}$ (CUNHA et al., 1985), chamados de N1, N2, N3, N4, N5, etc. (Figura 1).

\section{Clima}

A região de Carajás está submetida a um clima tipicamente tropical, quente e úmido, enquadrando-se na classificação de Köppen como tipo "Aw". As variações termais diárias vão de $24,30 \mathrm{OC}$ a
28,30C. A precipitaçāo pluviométrica média anual é de $2.116 \mathrm{~mm}$. Os meses mais secos vão de junho a setembro. A umidade relativa do ar é superior a $80 \%$.

\section{Solo}

A maioria dos solos da Serra dos Carajás enquadra-se no tipo Podzólico Vermelho-Amarelo (PV); nas áreas de cimeiras florestais encontra-se o Latossolo Vermelho-Amarelo distrófico: nos morrotes, cristas dessecadas subrochosas das margens da serra, ocorrem os Solos Litólicos Distróficos e nos níveis mais baixos das colinas. Solos Podzólicos Amarelos e VermelhoAmarelos. A canga hematítica ocorre nas áreas de relevos residuais, formando uma camada impermeável que em Carajás atinge uma profundidade de 5 a $20 \mathrm{~m}$ (BEISIEGEL et al., 1973), onde a camada de solo é muito rasa, o que impede a retenção da água pluvial (RIZZINI, 1976).

\section{Vegetação}

A vegetação de Carajás pode ser classificada em dois grandes grupos. como segue: 1. "Floresta Equatorial Ombrófila" e 2. "savana metalófila", ou "campo rupestre". vegetação "rupestre" ou, simplesmente, "vegetação de canga" (SECCO \& MESQUTTA 1983). Segundo AB'SABER (1986) a área florestal ocupa um espaço superior a $95 \%$ do total e o restante. cerca de 2 a $3 \%$, é formado por clareiras naturais de vegetação "rupestre". Estas situam-se nas cimeiras dos relevos residuais rochosos ou sub-rochosos, cujo solo é de canga hematítica. No presente trabalho, preferimos utilizar o termo vegetação "rupestre", já que a terminologia exata está ainda em discussão. 


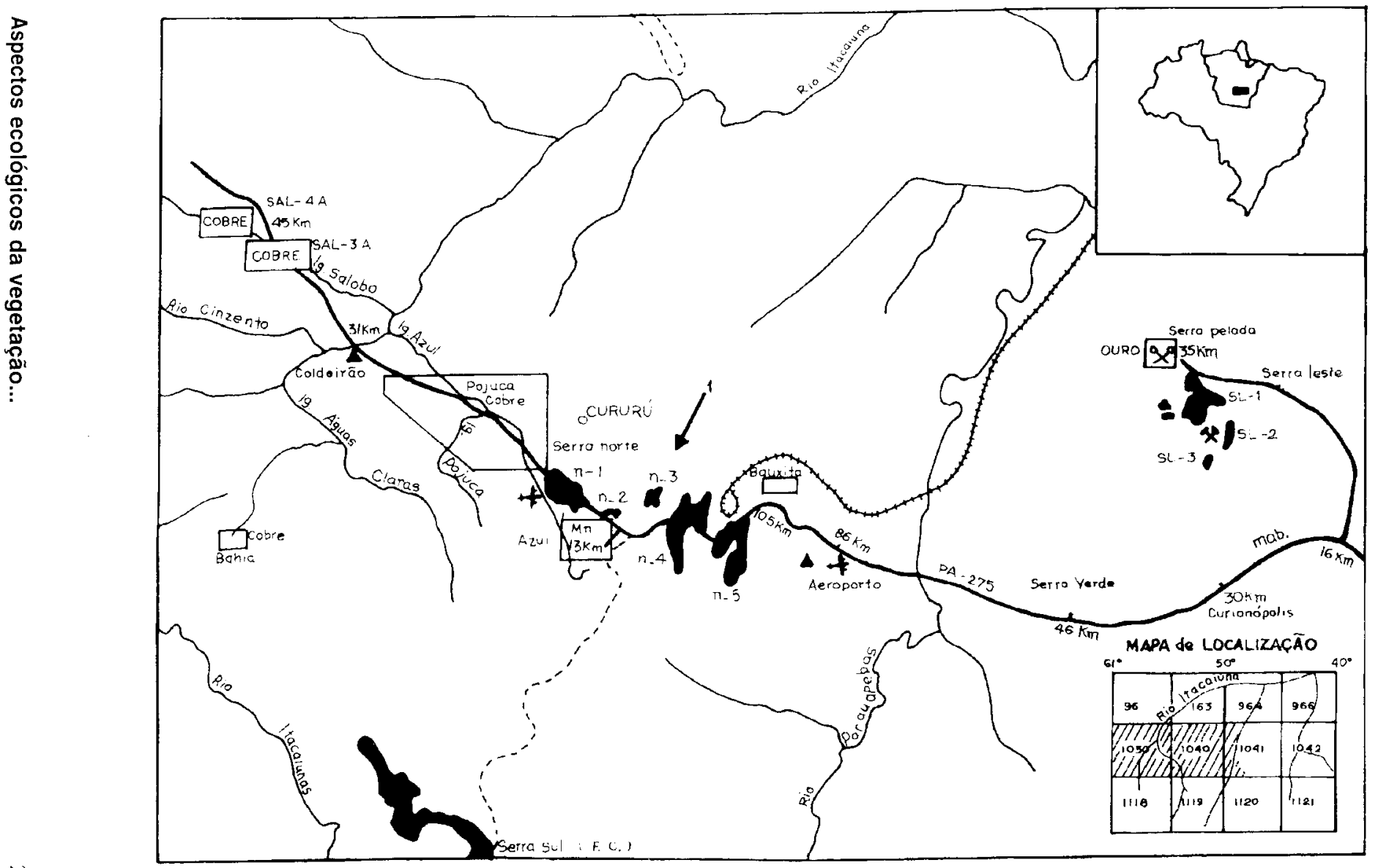

근 Figura 1. Mapa do complexo Carajás e principais depósitos de minério. Setal: jazida de ferro N3 


\section{Composição Florística}

$\mathrm{Na}$ vegetação rupestre foi registrado um total de 232 espécies, sendo 168 dicotiledôneas distribuídas em 109 gêneros e 47 famílias botânicas: 64 monocotiledôneas, distribuídas em 35 gêneros e 12 famílias e uma única espécie de pteridófita.

Um grande número de espécies registradas é composto de ervas anuais, cuja fase vegetativa restringe-se à determinada época do ano, ou seja, ao período de maior pluviosidade local. Estas espécies evidenciam uma relação muito estreita entre a composição florística da comunidade e as condições ambientais locais, no caso, a disponibilidade de água no substrato.

Na Tabela 1 estão relacionadas todas as famílias e respectivos gêneros e espécies amostrados. Houve uma grande amplitude de variação no número de espécies por familia. As duas famílias mais ricas apresentaram 24 espécies cada uma. Dezessete famílias $(29,31 \%$ do total) apresentaram uma única espécie, e vinte delas $(34,48 \%$ do total) tiveram duas espécies. Apenas dezenove famílias $(32,75 \%$ do total) apresentaram quatro ou mais espécies. Supõe-se que as condições ambientais adversas provenientes do substrato de canga exerçam uma alta pressão seletiva. Raras espécies de cada família foram capazes de se adaptar às condições locais. Poucas foram as exceções. como as famílias Gramineae e Leguminosae que apresentaram 24 espécies cada uma, correspondendo a $20.69 \%$ do total das espécies amostradas. A riqueza da família
Gramineae na vegetaçāo estudada é maior que naquelas reportadas para outras áreas de savana na Amazônia. EGLER (1960) registrou 15 espécies nos campos do Ariramba-PA e TAKEUCHI (1960) encontrou 17 espécies nas savanas da Amazônia Ocidental. Em outros casos, o número de espécies da família Gramineae é bem mais elevado que o reportado no presente estudo. GOODLAND \& FERRI (1979) citam um total de 73 espécies registradas nos cerrados do Triângulo Mineiro. JANSSEN ( 1986) inventariou 88 espécies de Gramineae nas savanas de Humaitá (AM). Esta família apresenta características que são responsáveis por sua alta adaptabilidade a curtos períodos de solo úmido e, conseqüentemente, por sua expressividade na comunidade em estudo. Muitas destas espécies foram esporadicamente registradas em determinados locais, mostrando-se assim, de ocorrência agregada nos locais cujas condições ambientais são favoráveis. A maioria das espécies de Gramineae ocorre onde o relevo permite acúmulo de água, pelo menos durante a época chuvosa. Nas áreas cujo relevo é escarpado e convexo, só quatro espécies de Gramineae foram registradas e destas somente Axonopus cf. leptostachyus (Flugge) Hitch. e Trachypogon macroglossus Trin. apresentaram ampla distribuição em toda a área amostrada. Estas duas espécies, segundo SILVA et al. (1986), possuem mecanismos fotossintéticos do tipo $\mathrm{C} 4$, o que thes confere a capacidade de habitarem ambiente adverso com um período crítico de falta d'água no substrato. 
O tipo de sistema radicular das Gramineas, formando uma vasta "cabeleira" superficial, é uma outra característica que confere à algumas espécies a capacidade de habitar tipo de ambiente como o da canga. As raízes aderem-se facilmente à superfície rochosa, em muitos casos, não necessitando do solo mineral propriamente dito como fonte de nutrientes minerais. Suas raízes em profusão e superficiais são capazes de absorver eficientemente os nutrientes que se encontram em solução no substrato. Estes nutrientes podem ser oriundos de outros locais, carreados pela água pluvial, ou podem ser reciclados do próprio material orgânico ou biomassa local.

Nos Campos do Ariramba (PA), cujo solo é do tipo canga como em Carajás, EGLER (1960) registrou espécies de Gramineae comuns àquela região, como: Ichnanthus axillaris (Nees) Hit., Panicum parvifolium Lam., Paspalum carinatum Flugg. e os gêneros Axonopus e Trachypogon, cuja distribuição é muito ampla em todas as regiōes tropicais.

Ainda com relação à família Gramineae, embora sendo uma das mais importantes na flora em estudo, nem todos os gêneros são igualmente importantes. Os mais destacados são Trachypogon e Axonopus, sendo que T. macroglossus e $A$. cf. leptostachyus foram as espécies mais expressivas, ambas estando presentes na maior parte da área estudada.

A família Leguminosae está representada da seguinte forma: subfamília Caesalpinioideae - quatro gêneros e oito espécies; sub-família
Mimosoideae - dois gêneros e cinco espécies e sub-família Papilionoideae nove gêneros e onze espécies. Em vegetação savanóide, no Brasil, esta família não é tão expressiva quanto em floresta. Das 24 espécies mencionadas nem todas são de importância marcante na flora estudada. As espécies Cassia calycioides DC., Parkia platycephala Benth., Centrosema carajasensis P. Cavalcante e Aeschynomene sp. foram registradas esporadicamente na vegetação sobre canga de Carajás, ocorrendo em locais restritos.

Segundo RIZZINI (1963), o gênero Cassia figura entre os mais ricos em número de espécies do cerrado. É também citado para outras áreas de vegetação não florestal, que inclui: savanas da Costa do Marfin e Suriname, Caatingas do Nordeste brasileiro, Savanas da Amazônia Ocidental e Campos do Ariramba, no Estado do Pará. É um gênero de ampla distribuição geográfica e habita ambientes diversos. Porém, na comunidade vegetal em estudo mostrou-se pouco expressivo tanto em riqueza de espécies como em frequiencia. No local ele foi representado por apenas duas espécies: $C$. calycioides e Cassia sp.. A primeira é amplamente distribuída em vários estados brasileiros e em diversos tipos de habitat. O gênero Centrosema ficou representado apenas por duas espécies; porém na flora local é um gênero que merece destaque. Sua ocorrência em áreas de savana não é muito comum. O número total de espécies do gênero na Amazônia é de aproximadamente nove. $C$. carajasensis é uma espécie nova para a ciência, cujo material-tipo foi coletado nas formações abertas de 
Carajás; é bem possível tratar-se de uma espécie endêmica daquela região. Segundo sua descrição original (CAVALCANTE, 1970), parece ser a primeira espécie de Centrosema unifoliolada da Amazônia brasileira.

Algumas espécies da família Leguminosae, que constam deste trabalho, foram registradas esporadicamente, sendo de importância secundária na flora local. São ervas anuais de ocorrência restrita e em número reduzido. São elas: Chamaecrista flexuosa (L.) Greene, C. cf. trichopoda (Bentham) I. \& B., Camptosema nobilis Lind., Phaseolus linearis H.B.K. e Stylosanthes humilis H.B.K. A espécie Sclerolobium paniculatum Vog. embora tenha sido encontrada raramente, é uma espécie importante na flora estudada, pois parece ser um elemento arbóreo típico de savana. No presente estudo, sua ocorrência limitou-se ao local com maior concentração de árvores, alcançando porte arbóreo, apresentando também representantes no estrato herbáceo (regeneração). Sclerolobium paniculatum é reportada por EGLER (1960) para os campos do Ariramba (PA); por JANSSEN (1986) como parte da flora das savanas de Humaitá (AM) e por RATTER (1987) como árvore do cerrado (MT).

O gênero Mimosa, sem dúvida é o mais interessante dentro das Leguminosae na flora em estudo. As três formas de vida registradas são representadas por três novas variedades, sendo que $M$. acutistipula var. ferrea Barneby e $M$. desmodioides var. carajarum Barneby são de Carajás e parecem ser endêmicas da flora local. Mimosa acutistipula var. ferrea é muito próxima de Mimosa acutistipula var. nigra Hub., anteriormente citada por VELOSO (1974) como vicariante das caatingas do Piauí. Esta espécie figura entre as mais importantes do estrato arbóreo-arbustivo, sendo também significativa no estrato inferior. Mimosa somnians var. viscida Barneby, conquanto não seja endêmica de Carajás, tem sua localidade-tipo naquela região. Segundo BARNEBY (1985) sua distribuição geográfica é a seguinte: Bahia, nas escarpas do Espigão Mestre; Goiás, onde é extremamente abundante; Pará, Serra dos Carajás; Guiana Francesa e Paraguai.

Dioclea cf. crenata Maxwell é uma espécie próxima à $D$. virgata (Rich.) Amsh. e Periandra mediterranea (Vell.) Taubert próxima à $P$. dulcis Benth. Sendo a primeira uma liana e a segunda um subarbusto sem potencial arbóreo, ambas perenes, resistentes à falta de água no substrato, de frequiência média, o que pode ser inferido como de distribuição regular na área de estudo.

Bauhinia pulchella Bentham foi a espécie melhor distribuída entre todas as amostradas, demonstrando alta adaptabilidade ao ambiente rupestre. Foi registrada em toda a área estudada. Esta espécie, juntamente com Dioclea cf. crenata, Periandra mediterranea. $M i$ mosa acutistipula var. ferrea e $M$. somnians var. viscida são as leguminosas verdadeiramente características da vegetação aberta de Carajás.

Outras famílias bem representadas foram as seguintes: Cyperaceae, com 15 espécies e seis gêneros, Myrtaceae com onze espécies e três gêneros, Rubiaceae com onze espécies pertencentes a oito 
diferentes gêneros, Bignoniaceae com oito espécies e seis gêneros. Malpighiaceae com oito espécies e cinco gêneros, Euphorbiaceae nove espécies e seis gêneros. Compositae sete espécies e cinco gêneros. Entre estas familias. a maioria tem ampla distribuição geográfica, sendo consideradas as maiores famílias botânicas do mundo. São elas: Compositae, Orchidaceae, Gramineae, Euphorbiaceae, Rubiaceate. Leguminosae, Myrtaceae e Cyperaceae. Bignoniaceae e Malpighiaceae, embora figurem entre as mais ricas no presente estudo, no âmbito mundial são inexpressivas. Elas foram reportadas por GOODLAND \& FERRI (1979) como "superrepresentadas" no cerrado. Aqui, evidentemente, não é correto usar a expressão "super-representada", mas aquelas familias são bem representadas por espécies características do tipo de comunidade em estudo.

A família Rubiaceae apresentou onze espécies em toda área de estudo. Este número é relativamente alto se for considerada a riqueza da maioria das familias aqui registradas. $\mathrm{Na}$ vegetação do cerrado esta família apresenta 17 espécies. sendo os gêneros Borreria e Alibertia importantes na flora daquela área (GOODLAND \& FERRI, 1979). Todas as espécies de Rubiaceae registradas no presente estudo são plantas de pequeno porte. a maioria ervas de ciclo de vida anual e de distribuição restrita a locais específicos com acúmulo de água. O gênero Borreria é pantropical e de ocorrência comum em áreas abertas como o cerrado e as campinas amazônicas. Borreria foi reportado por JACOBSEN (1970) habitando as minas de cobre de Silverside, porém não é um elemento que caracteriza a flora em estudo. Foram registradas em Carajás somente duas espécies de Borreria com pouquíssimos indivíduos ocorrendo em locais restritos. As espécies $B$. aff. tenera DC. e $B$. latifolia (Aubl.) R. Sch. ocorrem em determinados locais restritos nas áreas inventariadas. Esta última ocorre também nas savanas de Humaitá - AM (JANSSEN, 1986). O gênero Alibertia apresentou apenas uma espécie, $A$. longiflora R. Sch., um subarbusto perene, bem resistente às condições adversas do solo de canga. Da família Rubiaceae esta é a espécie que melhor caracteriza a vegetação em estudo. Perama carajuensis Kirkbride é uma nova espécie descrita por KIRKBRIDE (1980), cuja localidade-tipo é Carajás. Talvez seja mais um caso de endemismo da região. A espécie é bem representada na flora em apreço, ocorrendo só nos locais onde é possível a retenção de água por algum tempo.

A familia Orchidaceae apresentou seis espécies habitando, preferencialmente, lugares abertos, com bastante luminosidade. As espécies de Orchidaceae aqui registradas são de ocorrência esporádica nas áreas estudadas, com exceção de Sobralia liliastrum Lindl., que é um elemento característico tanto da flora quanto da vegetação local. Esta espécie tem ampla distribuição nas savanas amazônicas. EGLER (1960) registrou-a nos campos de Ariramba (PA).

A família Compositae foi representada por sete espécies distribuídas 
entre cinco gêneros. Segundo GOODLAND \& FERRI (1979), a família Compositae é a segunda ou terceira mais importante no cerrado. Os autores citam o gênero Vernonia como o mais importante das Angiospermas do Brasil, possuindo mais de 1.000 espécies distribuídas no mundo todo. Foram registradas três espécies de Vernonia em Carajás, contra 14 no cerrado do Triângulo Mineiro. Destas três espécies, só $V$. muricata DC. é expressiva na flora local e encontra-se bem distribuída em toda a área estudada, principalmente nos locais escarpados. É um subarbusto delgado, ramificado desde a base, altamente adaptado ao ambiente adverso de canga; possui raízes resistentes, fibrosas, capazes de penetrar nas fendas das rochas; perde as folhas e as terminações dos ramos na época seca, voltando a emitir novas folhas na estação chuvosa. As outras duas espécies, $V$. paraensis $\mathrm{H}$. Robson e $V$. remotiflora Rich. são pouco expressivas e foram amostradas em áreas restritas, nos locais onde é possível acumular água durante um certo período.

Riencourtia glomerata Cass. é uma outra espécie da família Compositae importante na vegetação em estudo. A ocorrência desta espécie foi estreitamente relacionada à presença de água no substrato. Foi registrada em grandes aglomerados, nos locais de maior disponibilidade de água. É uma espécie de ciclo de vida restrito ao período de chuva.

As demais espécies da família Compositae foram pouco expressivas, com reprèsentatividade reduzida tanto na florística quanto na fisionomia da vegetação local. Ichthyothere terminalis Blake foi citada por DONSELAAR (1969) para as savanas do Suriname e por JANSSEN (1986) para as savanas de Humaitá-AM. Porém, em Carajás, a presença desta espécie foi pouco expressiva.

A família Euphorbiaceae no presente estudo ficou representada por nove espécies, distribuídas entre 6 gêneros. O gênero Croton apresentou quatro espécies: $C$. aff. agrophilus Muell. Arg., C. tomentosus Link.. C. ferrugineus H.B.K. e C. jatropha H.B.K. Este gênero é de ampla distribuição em áreas de vegetação aberta. Foi citado por LIMA (1954) para as caatingas do sertão e restingas do nordeste brasileiro; por FERRI (1978) e GOODLAND \& FERRI (1979) para o cerrado; por DONSELAAR (1969) para o Suriname e por JANSSEN (1986) para Humaitá (AM). Croton aff. agrophilus e C. tomentosus são muito importantes nas áreas não florestais de Carajás. podendo ser consideradas espécies bem características daquela flora. São subarbustos lenhosos, perenes, resistentes, com deciduidade parcial durante a época seca, amplamente distribuídos em toda a área de canga. Alchornea discolor Poeppig. é uma Euphorbiaceae de pouca expressão na flora local, mas parece ser um elemento típico de savana. No presente estudo foi registrada compondo o estrato inferior. Porém. em outros locais desenvolve porte arbustivo. como nas savanas de Humaitá (JANSSEN, 1986) e no cerrado (RATTER, 1987).

Aparisthmium cordatum (Juss.) 
Baill., embora registrada na vegetação aberta, é na realidade uma espécie colonizadora de áreas florestais. Sua ocorrência foi divulgada por SILVA (1988) em quase toda a região florestal de Carajás, principalmente em áreas de clareiras. Nas áreas de savanas esta espécie ocorre participando dos "capões arbóreos", em aglomerados restritos aos locais onde o solo orgânico é profundo. As demais espécies da família Euphorbiaceae foram pouco expressivas na flora estudada.

A família Malpighiaceae foi bem representada nesta pesquisa, com oito espécies distribuídas entre cinco gêneros. Segundo RIZZINI (1963), o gênero Byrsonima é um dos mais bem representados no cerrado. Byrsonima coriacea (Sw.) Kunth é a espécie mais típica da vegetação em apreço. É um arbusto perene, sempreverde, alcançando o porte de árvore, tortuoso, muito ramificado, casca espessa e fissurada, semelhante à espécie $B$. crassifolia H.B.K. citada para os campos do Ariramba (PA) por EGLER (1960) e para as savanas do Suriname por DONSELAAR (1968). Byrsonima coriacea foi registrada tanto no estrato arbóreo-arbustivo quanto no estrato inferior e é bem distribuída em toda a área. Mascagnia sp. e Tetrapterys mucronata Cav. apresentam-se bem distribuídas na região amostrada.

A família Myrtaceae foi bem representada pelos gêneros Campomanesia, Eugenia e Myrcia, com elementos arbustivos e subarbustivos. As espécies destes três gêneros, embora não tão abundantes, caracterizam bem a flora em estudo. São perenes, distribuídas em toda área de canga, e perdem parcialmente as folhas na época seca. A espécie Eugenia punicifolia (H.B.K.) DC. é comum às savanas de Humaitá (JANSSEN, 1986). As espécies Myrcia cf. falax (Rich.) DC. e Eugenia flavescens DC. estão registradas nos herbários da região (MG e INPA), ocorrendo em áreas abertas, em diversos tipos de solo.

A família Bignoniaceae é representada, principalmente, por Anemopaegma aff. scabriuscula Mart. ex DC. Ao contrário do cerrado, cujos representantes desta família são árvores que caracterizam bem aquele tipo vegetacional, aqui a espécie mais expressiva, A. aff. scabriuscula é um arbusto delgado, semi-escandente, e encontra-se bem distribuído em toda área de canga; é perene e adaptado às condições ambientais locais.

A família Cyperaceae, embora bastante rica (15 espécies), não se configura como representante típica da vegetação em estudo como um todo. Esta família caracteriza um grupo específico dentro da vegetação aberta, denominado de campos naturais, que é uma vegetação graminosa restrita aos locais de relevo plano ou côncavo, permitindo o acúmulo de água durante o período chuvoso. Nenhuma espécie de Cyperaceae foi registrada em áreas cujos relevos não permitem a retenção de água.

A família Convolvulaceae, embora não tão rica em espécies, é uma das que mais caracterizam a flora em estudo. Está representada por cinco espécies, sendo que quatro pertencem ao gênero Ipomoea e a quinta espécie é do gênero Evolvulus. As espécies $I$. carajasensis D. Austin, I. cavalcantei 
D. Austin e I. marabaensis D. Austin \& Secco são espécies novas descritas a partir do material coletado em Carajás (AUSTIN, 1981; AUSTIN \& SECCO, 1988), sendo consideradas até o presente momento como endêmicas daquela região e daquela comunidade vegetal. As duas primeiras são amplamente distribuídas em toda a área estudada, principalmente nos locais bem abertos, enquanto que I. marabaensis tem ocorrência restrita a certos locais. Vale salientar que 1 . marabaensis é uma espécie polimorfa e apresenta uma certa semelhança com I. cavalcantei, que já é um símbolo do "campo rupestre" de Carajás, diferindo imediatamente por apresentar corola maior, infundibuliforme, sépalas também maiores e os estames inclusos no tubo da corola. Do ponto de vista conservacionista, estas espécies figuram entre as que demandam grande atenção. Por nunca terem sido registradas em outras regiōes, podem ser consideradas em risco de extinção. Ocorrem exclusivamente sobre as jazidas de ferro. O gênero Ipomoea é reportado para outras áreas de jazidas minerais, como as minas de cobre do Zaire e da Rodésia (WILD 1968/69; BROOKS et al. 1980), o que demonstra a capacidade do mesmo de habitar tais ambientes.

A família Melastomataceae é bem representada na flora brasileira, porém na área estudada foram registradas somente sete espécies. Os gêneros Aciotis, Miconia e Tibouchina são de ocorrência comum em vegetação savanóide. A espécie T. aspera Aubl. é um elemento bem característico da vegetação em análise; é um arbusto perenifólio, regularmente distribuído em toda a área de canga, demonstrando preferência ao ambiente adverso dos locais escarpados e deficientes em água, pelo menos durante uma estação. Segundo RIZZINI (1976) o gênero Tibouchina é um exemplo de arbusto xerofítico. A espécie T. aspera foi registrada nos campos do Ariramba - PA (EGLER, 1960); nas savanas do Suriname (DONSELAAR, 1969) e nas savanas de Humaitá-AM (JANSSEN, 1986).

A família Erythroxylaceae ficou representada por quatro espécies, sendo que Erythroxylum ligustrinum var. carajasense Plowman e E. nelsonrosae Plowman são novos táxons descritos para a flora de Carajás (PLOWMAN, 1986). São espécies consideradas endêmicas da área. Ambas são perenes, perdendo parcialmente as folhas durante a estação seca e bem distribuídas em toda a área de canga.

Um número expressivo de famílias apresentou número de espécies muito reduzido. Entre estas famílias, algumas são de grande importância na flora local como um todo, outras caracterizam determinado grupo dentro da vegetação e outras são pouco expressivas da flora em estudo. As famílias serão agrupadas a seguir como:

Famílias cujos representantes são, comumente, elementos arbóreos registrados esporadicamente, fazendo parte do grupo "capões de árvores" ou isolados, ou ainda típicos de áreas transicionais com a floresta:

Anacardiaceae, representada por Anacardium microcarpum Ducke e 
Tapirira guianensis Aubl. Anacardium microcarpum é uma espécie típica de ambiente xerofítico e sua ocorrência tem sido bastante divulgada em áreas de cerrado (RIZZINI, 1963, 1976: GOODLAND \& FERRI, 1979; RATTER, 1987). Segundo PIRES \& PRANCE (1985), é uma espécie típica de savana. Tapirira guianensis : $111 \mathrm{~m}$ das poucas espécies arborcis registradas, de ocorrência rara e/ou restrita aos "capões de árvores.". Segundo LIMA (1954) esta é uma espécie de floresta. Porém, tem sido registrada em vegetação savanóide (EGLER, 1960; JANSSEN, 1986). Nos herbários da região sua distribuição é registrada em mata de terra firme, campos rupestres e campina.

Rutaceae, com as espécies Pilocarpus sp. e P. microphyllus Stapf. ex Wald. Esta família parece não caracterizar a vegetação em apreço. As duas espécies supra-citadas foram registradas esporadicamente. Pilocarpus microphyllus é reconhecidamente uma planta do sub-bosque da floresta; no presente estudo sua ocorrência deu-se nas áreas transicionais da canga com a floresta, em locais semi- sombreados.

Sapotaceae, com três espécies. Franchetella parviflora Pires, é uma das poucas espécies formadoras do estrato arbóreo da área de savana. Possui tronco tortuoso, casca espessa, fissurada. folhas crassas. que são características adaptativas à ambientes xéricos (RIZZINI, 1963).

Vochysiaceae, representada por uma espécie indeterminada e por Callisthene minor Mart., que é de grande importância na vegetação em estudo. É o principal componente do estrato arbóreo. Taxonomicamente, esta espécie está próxima a $C$. microphyllus, que, segundo PIRES (1973), é um elemento característico das caatingas do Piauí.

Famílias cuja maioria das espécies está distribuída em toda a vegetação savanóide, principalmente nos locais escarpados. São, normalmente, escandentes ou pequenos arbustos, perenes, com adaptações xeromórficas bem visíveis. São incluídas neste grupo famílias cujos representantes são de ocorrência esporádica, porém assemelham-se fisionomicamente às espécies do cerrado, mostrando-se bem adaptadas às condições xerofíticas. Estas famílias são as seguintes:

Apocynaceae, representada na vegetação aberta de Carajás por quatro espécies.

Araceae, representada pelas espécies Anthurium solitarium (Vell.) Schott. e Philodendron sp.

Bromeliaceae, representada por qautro espécies, sendo duas bem distribuídas na vegetação em estudo. São elas: Ananas ananassoides (Bakes) L.B. Smith e Dyckia duckei L.B. Smith, ambas perenes e muito resistentes à falta de água. Ananas ananassoides ocorre também nas savanas de Humaitá (JANSSEN, 1986) e D. duckei nos campos do Ariramba (EGLER, 1960).

Cactaceae, com as espécies Pilocereus sp. e Phyllocactus phylanthus (L.) Link, de ocorrência esporádica.

Lythraceae, com duas espécies: Cuphea annulata Koelme e C. tenella Hook \& Am., ambas bem representadas 
na área estudada. São subarbustos perenes que perdem parte da folhagem e terminações dos ramos na estação seca. São bem ramificadas desde a base. Embora estas espécies pareçam bem adaptadas ao ambiente savanícola, não são citadas para outras savanas.

Marcgraviaceae, representada por uma única espécie: Norantea goyazensis Cambess., que é um vegetal de hábito de crescimento muito singular. Sua forma mais expressiva é como arbusto de 1,00-1,80 $\mathrm{m}$ de altura, copa bem conformada, a partir da qual alguns ramos tornam-se escandentes e decumbem sobre as rochas, passando a crescer em forma de liana, alcançando até $10 \mathrm{~m}$ de comprimento; em seguida, há emissão de raízes na região das gemas axilares; com o passar do tempo a região entre os nós morre, então as gemas aí existentes brotam dando origem a novos indivíduos, representando um tipo de propagação vegetativa. A espécie floresce nos meses de agosto e setembro, época mais seca na região.

Velloziaceae apresenta as espécies Vellozia sp. e V. glochidea Pohl. Esta última ocorre mais abundantemente que a primeira. São plantas tunicadas, cujas bainhas das folhas são persistentes e sobrepostas formando um pseudo-caule. De acordo com RIZZINI (1976), esta família é comum nos campos elevados do Brasil. da África e dos Andes. Segundo JOLY (1970), o gênero Vellozia ocorre nos campos rupestres de Minas Gerais e Goiás. Este gêneru parece ser bem adaptado aos substratos rochosos sobre jazidas minerais, e foi reportado por DUVIGNEAUD (1958) para os solos metalíferos do Katanga (África); por HOWARD-WILLIAMS $(1970,1971)$ para as minas de cobre de South Hill (África Central); WILD (1968, 1969) para os solos de cobre da Rodésia; JACOBSEN (1970) para as minas de cobre de Silver Side, e WILD \& BRADSHAW (1977) para os solos de serpentina da Rodésia. Esta família parece ser característica de formações rupestres (ex. em Mato Grosso).

Verbenaceae, com duas espécies. Lippia grandis é bem adaptada às condições ambientais locais. É um subarbusto perene, distribuído em toda a área de canga, principalmente nos locais escarpados.

Vitaceae, representada pelas espécies Cissus erosa L.C. Rich. e $C$. sulcicaulis Baker, abundantes na vegetação de canga.

Famílias de ocorrência esporádica, restritas a locais especiais, normalmente onde é possível o acúmulo de água pelo menos durante um período do ano. Porém, nos lugares onde ocorrem são abundantes, dando idéia de aglomerados. Normalmente são ervas anuais, cujo ciclo vital se completa no período chuvoso. São elas: Begoniaceae (Begonia guianensis A. DC. e B. humilis A. DC.); Burmaniaceae (Burmania cf. bicolor Mart.); Eriocaulaceae (Paepalanthus of. fasciculatus var. icanensis Herzog, Syngonanthus gracilis (Bong.) Ruhl., $S$. caulescens var. angustifolia e Eriocaulon affaquatile Koern.): Gentianaceae (Schultesia pohliana Pr. e Limnanthemum humboldtianum Griseb.); Lentibulariaceae (Utricularia sp., U. nervosa G. Web., U. subulata 
L., U. obtusa Sw.); Ochnaceae (Ouratea castanaefolia (DC.) Engl., O. paraensis Hub. e Sauvagesia tenella Lam.); Polygalaceae (Polygala variabilis H.B.K. e P. spectabilis DC.); Turneraceae (Turnera glaziovii Urb. e Piriqueta cf. cistoides (L.) Griseb.) e Xyridaceae (Xyris aff. longiceps Malme e X. laxifolia Mart.).

Finalmente, as famílias de ocorrência esporádica. As espécies que compõem este grupo podem ser consideradas ocasionais. As famílias e respectivas espécies formadoras deste grupo são as seguintes: Acanthaceae (Ruellia sp.); Annonaceae (Guatteria poeppigiana Mart. e Xylopia sp.); Chrysobalanaceae (Licania egleri Prance e Acioa sp.); Dioscoreaceae (Dioscorea sp. e D. huberi R. Kunth); Flacourtiaceae (Casearia arborea (L.C. Rich.) Urban); Hippocrateaceae (Hippocratea cf. volubilis L.); Humiriaceae (Saccoglottis mattogrossensis Malme); Loranthaceae (Phthirusa paniculata (H.B.K.) Macbr.); Marantaceae (Maranta sp.) Menispermaceae (Cissampelos andromorpha DC. e Sciadotenia cf. paraensis (Eihl.) Dicl.); Nyctaginaceae (Neea sp.); Olacaceae (Heisteria ovata Benth.); Palmae (Oenocarpus distichus Martius); Polygonaceae (Coccoloba latifolia Lam.); Polypodiaceae (Polypodium triseriale Sw.); Proteaceae (Roupala montana Aubl.); Smilacaceae (Smilax campestris Griseb.) e Sterculiaceae (Melochia villosa (Will.) Fawc. \& Rendle.

Muitas das espécies registradas na flora em estudo apresentam-se amplamente distribuídas em outras regiões, a maioria fazendo parte de comunidades vegetais abertas como: campina (caatinga amazônica, AM); cerrado, campo rupestre, etc., sendo menos comum em áreas florestais. Porém, espécies típicas de savanas como Hancornia speciosa, Curatella americana, Qualea grandiflora, Byrsonima crassifolia, Antonia ovata, Tabebuia caraiba, Salvertia convallariodora, Palicourea rigidifolia (EGLER, 1960; DONSELAAR, 1969; LEDOUX, 1969; PIRES \& PRANCE, 1985; JANSSEN, 1986) não foram registradas na flora de Carajás. No entanto, estas espécies são citadas para outras áreas da Amazônia, como os campos do Ariramba (EGLER, 1960), as savanas do Amapá (LEDOUX, 1969), as savanas de Humaitá (JANSSEN, 1986) e as savanas de Roraima (RODRIGUES 1971), onde também ocorrem várias outras espécies comuns a Carajás.

A flora estudada de Carajás apresenta um número expressivo de prováveis endemísmos. Já foram descritos dě novos táxons para aquela área. $\mathrm{A}$ maioria dessas espécies é de ocorrência restrita a Carajás e consideradas, até o momento, como endêmicas.

$O$ alto grau de endemismo sugere que esta vegetação isolada sofreu um processo de especiação devido às pressões ambientais locais, resultando em um número expressivo de novos táxons.

\section{Polinização e Dispersão (Notas preliminares)}

Em seguida forneceremos algumas informações preliminares sobre polinização e dispersão resultantes de recente trabalho 
de campo na Serra dos Carajás.

A oferta de pólen e néctar é grande na época úmida, quando as plantas utilizam as mais variadas estratégias de atração aos polinizadores. No caso daquelas cujas flores são brancas ou pálidas e pequenas, é muito comum reunirem-se em aglomerados, compondo um tapete de atração, como nas espécies de Riencourtia, Borreria, Richardia e certas Eriocaulaceae (com capítulos marrons-pálidos). Em Perama carajaensis Kirkbride temos inflorescências delicadas em "candelabros", que se agrupam formando uma "nuvem" de pequenas flores brancas. Algumas espécies recorrem a síndromes que lembram a forma de insetos, como certas Leguminosae cujos estames estão retidos no interior de pétalas especializadas (vexilos) e a morfologia floral imita o aspecto de borboleta. Outras, com flores inconspícuas, como Lippia grandis Schaw (planta medicinal) exalam cheiro do óleo essencial que contém, o que parece ser uma estratégia de atração aos polinizadores. As lpomoea formam um grupo à parte, possivelmente o mais expressivo da vegetação "rupestre" de Carajás, em termos de modo de atração ao agente polinizador. Suas corolas sempre bem coloridas, quer espalhadas rasteiramente ou aderidas em outras plantas, são bastantes atrativas para os insetos. Ipomoea cavalcantei Austin, além de sua flor muito atraente, de cerca de 4 a $5 \mathrm{~cm}$ de comprimento, de cor púrpura brilhosa, apresenta estames expostos acima da constrição da corola e o hábito rastejante e volúvel, enramando-se em qualquer espécie mais próxima, garantindo uma exposição máxima aos polinizadores. Por outro lado, os estames dessa espécie são muito apreciados por insetos, sendo bastante comum encontrá-los roídos nas corolas. Pareceu-nos um caso interessante de associação planta/inseto, pois os insetos participam da polinização da planta, obtendo estames e néctar (através do ato de roer o tubo das corolas) como alimento. As demais Ipomoea de Carajás mantêm os estames na parte interna da corola tubulosa.

Além de suas inflorescências em espigas brancas e vistosas, Mimosa acutistipula exala um perfume adocicado que pode funcionar como uma possível atração aos polinizadores. Mimosa somnians H.B.K. tem seus capítulos rosados, bem destacados na paisagem, e sua floração não ocorre simultaneamente com $M$. acutistipula. Então, o odor e a época de floração diferente também parecem contribuir como estratégias utilizadas pelas plantas rupestres visando a polinização. Melochia villosa, com seu crescimento esquarroso (espalhado), com os ramos dispondo-se de modo estrelado, parece evidenciar uma estratégia de polinização na vegetação "rupestre" de Carajás. No caso de Croton $\mathrm{sp}$, planta de alta resistência às adversidades de solo e temperatura nos campos, seus estames branco-leitosos, pequeninos, expõem-se ao máximo em substituição às pétalas que são ausentes.

É preciso salientar que inúmeras espécies, entre essas as Leguminosae (Mimosa acutistipula var. ferrea e Bauhinia pulchella), têm anteras 
versáteis, o que lhes possibilita a polinização pelo vento. Outras, mesmo com pequenas flores, como espécies de Cuphea, Burmania, etc., apresentam a coloração viva das corolas como estratégia de atração aos polinizadores.

Os frutos e sementes das plantas "rupestres" apresentam sempre adaptações que lhes permitem dispersão pelo vento, sendo estruturas levíssimas, na maioria dos casos. Os de Mimosa acutistipula são achatados, textura coriácea, muito leves, cor de vinho escuro, podendo ser levados à grande distância pelo vento na maturação. Os de Anaemopaegma aff. scabriuscula Mart. ex DC, embora sejam frutos grandes e um pouco pesados, são deiscentes e possuem sementes papiráceas, muito leves e aladas para flanar. Também nos frutos de Tetrapteris mucronata Cav. e das Begonia, em geral, encontramos alas. As sementes das Ipomoea são dotadas de cerdas, enquanto os frutos de Jacquemontia tamnifolia (L.) Griseb. apresentam papus pilosos para a dispersão à longa distância pelo vento. Os frutos de Vellozia glochidea Pohl. são duros, resistentes, muricados, mas deiscentes com sementes pequenas e leves, fáceis de serem levadas pelas correntes de ar. Os frutos de Croton tomentosus Link e de Callisthene minor Mart. abrem na maturação em três partes, liberando as sementes leves para o domínio dos ventos. O fruto de Mimosa somnians var. viscida, do tipo craspédio, é seccionado para facilitar a liberação da semente, enquanto o de Calopogonium muconoides é um legume.

A presença de pássaros na vegetação "rupestre" (ex. Poecilurus e Zonotrichia), inclusive encontrando-se ninhos, é um fator que deve contribuir principalmente com dispersão de frutos e sementes, como por exemplo de Myrtaceae e Vochysiaceae (Callisthene).

Em épocas intermediárias entre as duas estações (seca e chuvosa), nas quais poucas espécies melíferas estão florindo, as abelhas (Apis melifera L.) recorrem em massa à Borreria verticilata, a conhecida "vassourinha de botão", para coleta de néctar e pólen. Esta espécie possivelmente fica tendo uma importância relevante no fornecimento de matéria-prima para o fabrico de mel. uma vez que supre as necessidades alimentares desses insetos num período de escassa floração. Notamos que nas áreas de colonização, onde está bem marcada a presença do homem e da "vassourinha de botão", as abelhas trabalham intensamente nessas épocas.

Embora com a distribuição mais esparsa, Norantea goyazensis é também um foco de atenção para as abelhas, havendo participação de Apis melifera (abelha de maior porte) e certos meliponídeos (ex. Melipona seminigra pernigra Moure \& Kerre Trigona williana Friese), bem como beijas-flores na procura de néctar e pólen.

Com a continuidade das expedições realizadas à Serra dos Carajás, só fizemos amadurecer nossa opinião de que às manchas de "campos naturais" (SECCO \& MESQUTTA, 1983) deveria ser dado um tratamento mais enfático de natureza ecológica, isto devido aos interessantes fenômenos lá observados, como uma acentuada preferência de insetos, destacando-se abelhas, principalmente na floração, e cupins associados na maioria das vezes às Gramineae. Some-se a 
estes aspectos grupamentos definidos de certas espécies vegetais (ex. Cuphea tenella St. Hill., Riencourtia cf. glomerata Cambess., entre outras) que formam verdadeiros "feixes" floridos a atrair os polinizadores e que podem fornecer dados curiosos sobre biologia floral.

\section{Associação Planta, Solo e Cupins (Notas Preliminares)}

SILVA \& ROSA (1990) forneceram observações fitoecológicas sobre os "campos rupestres" (vegetação de canga) na Serra Norte, de um modo geral, enquanto BARTH (1987) coletou dados preliminares sobre a flora apícola da região.

A vegetação "rupestre", cujo tapete graminoso-ciperáceo está associado à certas dicotiledôneas herbáceas, apresenta extensas manchas palhosas de vegetação degradada à época seca. Com o retorno da estação chuvosa é comum indivíduos de $M i$ mosa acutistipula var. ferrea e Mimosa somnians var. viscida revelarem uma acentuada tendência a ocupar espaços nesses campos. Esses indivíduos podem se distribuir espaçadamente ou em grupos formando touceiras, "linhas contínuas" ou vigorosas populações. Mas apesar dessa invasão arbustiva e de certos grupamentos herbáceos (espécies dos gêneros Cuphea, Melochia, Riencourtia etc.), nota-se que os "campos naturais" são formações ecológicas bem definidas, sui-gêneris, cujo tapete graminosociperáceo tem relevante destaque em relação à vegetação "rupestre" mais arbustiva. SILVA \& ROSA (1990) citam que essas gramíneas têm mecanismos fotossintéticos especializados, via $\mathrm{C} 4$, o que thes possibilita superar principalmente a alta insolação e o déficit de água. A esse fato podemos acrescentar as suas raízes de crescimento espraiado, em cabeleira, o que lhes permite maior aproveitamento da ínfima camada de nutrientes do solo. E certamente os arbustos encontram limitação para se estabelecer neste tipo de ambiente, principalmente pelo seu sistema radicular que exige solos mais profundo e pelo seu sistema fotossintético possivelmente na grande maioria do tipo $\mathrm{C} 3$.

Além de uma insignificante camada lodosa, associada a musgos e líquens, observamos na transição entre as estações seca e chuvosa uma significativa quantidade de ninhos de cupins espalhados no solo da vegetação "rupestre", estendendo-se mais esparsamente nos troncos dos arbustos. Muitas vezes os cupins estão vivendo diretamente nas raizes de certos capins, tornando-os bastante viçosos. Este aspecto nos serviu como ponto forte para darmos mais atenção à referida vegetação. De acordo com BANDEIRA (1985) os cupinzeiros são fontes de nutrientes em solos pobres da Amazônia e ninhos de cupins analisados nas campinas da Zona Bragantina (Pará) revelaram uma alta concentração de matéria orgânica e nutrientes inorgânicos. O mesmo autor (comunicação pessoal) nos informou que esses termitas da Serra Norte são da espécie Nasutitermis minimus. As espécies de Byrsonima apresentam-se bem mais vigorosas quando assentadas em cupinzeiros. 


\section{CONCLUSÕES}

A retenção de água no solo limitada pela impermeabilidade do substrato canga hematítica e pelo relevo do terreno parece influenciar diretamente na composição florística e na fisionomia da vegetação. O substrato é uma camada rochosa de minério de ferro parcialmente intemperizada, formando uma camada impermeável que dificulta a retenção de água. Por outro lado, o relevo ondulado permite que nas áreas escarpadas a perda da água pluvial se faça muito rapidamente, enquanto que nas áreas planas e semicôncavas esta água pode ficar retida durante a estação chuvosa. A disponibilidade de água no substrato está relacionada diretamente à estação chuvosa. As espécies que compõem a comunidade são adaptadas às condições ambientais provenientes dessas condições edáficas adversas. As estratégias adaptativas utilizadas pelas mesmas são de duas ordens: um grupo restringe o período vegetativo a uma estação do ano, no caso à estação chuvosa: outro grupo é composto de espécies perenes, resistentes ao déficit hídrico do solo.

O primeiro grupo é formado de plantas anuais que completam um ciclo de vida durante o período de maior pluviosidade local. As espécies formadoras deste grupo aderem-se facilmente à superfície rochosa, principalmente entre as rochas e nas fendas das mesmas: a maioria distribui-se em toda a área de canga e foram registradas expressivamente na área de relevo semicôncavo, onde a água fica retida durante a estação chuvosa.

As espécies perenes encontramse amplamente distribuídas em toda a área de canga, independente da estação do ano; preferencialmente nas áreas escarpadas. Possuem um número variado de adaptações xeromórficas; são plantas tunicadas, com as gemas vegetativas protegidas por bainhas sobrepostas como as Velloziaceae; com gemas vegetativas sop o solo, ou na superfície do solo, $\rho$ que lhes permite reduzir a biomassa aérea (ramos e/ou folhas principalmente) durante a estação desfavorável. Entre as mesmas são comuns aspectos xerofíticos como casca espessa e fissurada, caules tortuosos e deciduidade foliar; estas características tornam o gupo muito semelhante às plantas do cerrado.

As famílias Gramineae e Leguminosae foram as mais importantes na flora analisada. Apresentaram o maior número de espécies nas áreas, sendo bem distribuídas no local.

Foram registrados 10 novos táxons na vegetação estudada, sendo a maioria espécies endêmicas da mesma. Este fato mostra que aquele tipo de vegetação é muito especializado do ponto de vista florístico.

A flora da vegetação "rupestre" de Carajás compõe-se de inúmeras espécies endêmicas, espécies raras, espécies novas para a ciência, espécies medicinais e ornamentajs. além de estar associada a uma fauna onde se destaca uma boa concentração de pássaros (ex. Poecilurus, Zonotrichia); insetos como abelhas (ex. Apis mellifera L.) meliponídeos (ex. Melipana seminigra pernigra Moure \& Kerr, Trigona williana 
Friese) e tabanídeos (ex. Cryptotylus); répteis (ex. Liophis carajasensis, tão peculiar à Serra Norte, Anolis chrysolepis, Kinosternon s. scorpioides), etc.

A singularidade deste tipo de vegetação demonstra tratar-se de um ecossistema muito frágil, sendo de vital importância a preservação de uma de suas áreas como Reserva Ecológica. Se a exploração mineral desestruturar esta comunidade, com certeza estarão desaparecendo da face da terra as espécies vegetais endêmicas daquela região.

\section{AGRADECIMENTOS}

Ao Dr. William L. Overal, pela versão do resumo para o inglês; ao Sr. Celso Moraes, pelo trabalho de digitação e aos "referees" pelas úteis sugestões fornecidas ao texto.

\section{Bibliografia citada}

AB'SABER, A.N. 1986. Geomorfologia da região. In: CARAJÁS: desafío político. ecologia e desenvolvimento. São Paulo: Brasiliense; Brasilia: CNPq. p. 88-124.

AUSTIN, D.F. 1981. Novidades nas Convolvulaccàe da flora amazônica. Acła Amazonica. Manaus, 11(2):291-295.

AUSTIN. D.F.: SECCO, R.S. 1988. Ipomoea marabaensis. nova Convolvulaceae da Serra dos Carajás (PA). Bol. Mus. Para. Emilio Goeldi. Sér. Bot., 4(2):187-194.

BANDEIRA. A.G. 1985. Cupinzeiros como fonte de nutrientes em solos pobres da Amazonia. Bol. Mus. Para. Emilio Goeldi, Sér. Zool., 2(1): 39-48.

BARNEBY, R.C. 1985. The Genus Mimosal (Mimosaceae), in Bahia, Brazil: New taxa and nomenclature adjustments. Brittonia, 37(2): 125-153.

BARTH. O.M. 1987. Importância apícola dos campos naturais e rupestres da Serra Norte de Carajás (PA). Bol. Mus. Para. Emílio Goeldi, Sér. Bot., 3(1):21-28.

BEISIEGEL, V.R.; BERNARDELLI, A.R.:
DRUMOND. N.F.: RUFF, A.W.: TREMAINE, J.W. 1973. Geologia e recursos minerais da Serra dos Carajás. Rev. Bras. Geociènc., São Paulo. 3(4):215-242.

BROOKS, R.R.: REEVES. R.D.: MORRISON, R.S.; MALAISSE. F. 1980. Hyperaccumulation of copper and cobalt - A Review. Bull. Soc. R. Bot. Belge, 113:166-172.

CAvalCANTE, P.B. 1970. Centrosema carajasense; uma nova leguminosac da Amazonia. Bol. Mus. Para. Emilio Goeldi, Nova sér. Bot., Belém, 37:1-4.

CUNHA, O.R.: NASCIMENTO, F.P: ÁVILAPIRES, T.C.S. 1985. Os réptets da área de Carajás. Pará, Brasil. (Testudines e Squimata). Publ. Avuls. Mus. Par: Emilio Gocldi, Belém, 40:9-92, il.

DONSELAAR. J. van. 1968. Phytogeographic notes on the savanna flora of Southern Surinam (South America). Acta Bot. Neerl., 17(5).

DONSELAAR, J van. 1969. Observation on savana vegetation-types in the Guianas: Vegetatio, $8: 271-312$.

DUVIGNEAUD, P. 1958. La végétation du Katanga el de ses sols métallifères. Bull Soc. R. Bot. Belge, 90:127-286.

EGLER, W.A. 1960. Contribuição ao conhecimento dos campos da Amazonia. I - Os Campos do Ariramba. Bol. Mus. Para. Emilio Goeldi. Botânica. 4:1-36.

FERRI. M.G. 1978. Ecologia comparada del "cerrado" y de la "caatingal. Memorias do Congresso Venesolano de Botanica. 5. Barquisimet. p. 189-243.

GOODLAND. R.: FERRI. M.G. 1979 Ecologia de Cerrado. Belo Horizonte. Ed. Itatiaia; São Paulo, Ed. da Universidade de São Paulo. 193 p.

HOWARD-WILLIAMS, C. 1970. The Ecology of Becium homblei in Central Africa with special reference to metallifcrous soils. Joum. Ecol. 58:745-763.

HOWARD-WILLIAMS. C. 1971. Environmental factors controlling the growth of plants on heavy metal soils. Kirkich 8:91-102. 
JACOBSEN. W.B.G. 1970. Further notes on the vegetation of copper bearing soils at Silverside. Kirkia, 7:285-290.

JANSSEN, A. 1986. Flora und Vegetation der Sarannen von Humaita and itre standorbedingungen. Dissertationes Bollanicae. Band 93. J. Cramer. Berlin. 321 p.. Tese (doutorado) Depto. de Biologia, Ludwig-Maxmilians Universiät.

JOLY. A.B. 1970. Conheça a vegetação brasileira. São Paulo, EDUSP, Polígono. 165 p.

KIRKBRIDE. J.H. 1980. Manipulus rubiacearum - I. Acta Amazonica, 10(1):97-118.

LEDOUX. P. 1969. Fitotopos nas savanas equatoriais do Amapá, com desenvolvimento arbóreo ao máximo do potencial específico. Ciênc. e Cult. 21(2):443.

LIMA. D.A. 1954. Contribution to the study of the Flora of Pemambaco, Brazil. State University of New York. Tese.

PIRES. J.M. 1973. Tipos de vegetaçāo da Amazônia. Publ. Alulsa Mus. Par Emilio Goildi. Belém, 20:179-202.

PIRES. M.P.: PRANCE, G.T. 1985. The Vegetation types of the hrazilian amazon. In: Amazonia. Oxford. Pergamon Press p. 109-145.

PLOWMAN, T, 1986. New taxa of Enthroxhm (Erythroxylaceac) fron the Amazon Basin, Acta Amazon., Manaus. 14(1-2):117-144. supl

PORTO. M.L.: SILVA, M.F.F. 1987. Tipos de vegetação metalófila da área da Serra dos Carajás e Minas Gerais. Resumos Congresso Nacional de Botânica. São Paulo: p. 38.

RATTER. J.A. 1987. Notes on the vegetation of the Parque Nacional do Araguaia (Brazil). Noles RBG Edinh., 44(2):311-342.

RELATÓRIO DO MUSEU GOELDI À COMPANHIA VALE DO RIO DOCE 1988. Belém (PA) v.1.

RIZZINI. C.T. 1963. A flora do cerrado. Simpósio where Cerrado. Editora da Universidade de São Paulo, S.P. p. 127-177.

RIZZINI. C.T. 1976. Trateder de Fitogeegrafia do
Brasil. São Paulo, HUCITEC, Ed. da Universidade de São Paulo. il.

RODRIGUES, W. 1971. Plantas dos campos do Rio Branco (Território de Roraima). In: FERRI. M.G. (cd). III Simpósio sobre o cerrado. Ed. E. Blücher Ltda., USP, São Paulo.

SECCO. R.S.: LOBO, M.G.A. 1988. Considerações taxonômicas e ecológicas sobre a flora dos "campos rupestres" da Serra dos Carajás. Bol. $F B C N$. Rio de Janeiro. 3(23):30-44.

SECCO, R.S.; MESQUITA, A.L. 1983. Notas sobre a vegetação de canga da Serra Norte. I. Bol. Mus. Para. Emílio Goeldi. Nova Sér: Bot. 59:1-13. il.

SILVA. M.F.F.: MENEZES, N.L.; CAVAlCANTE, P.B.; JOLY, C. 1986. Estudos Botânicos: histórico, atualidade e perspectivas. In: CARAJÁS: desafio politico, ecologia e desenvolvimento. São Paulo: Brasiliense: Brasilia: CNPq. p. 184207

SILVA. M.FF. 1988. Relatório Final do Projeto Carcijacs. Sub-Projeto Inventário Botânico. Convênio MPEG/CVRD, Contrato 16/83.

SILVA, M.F.F. da. 1989. Aspectos Ecológicos da vegetagão que cresce sobre Canga Hematítica a'm Carajás-PA. INPA/FUA. Tese de doutorado.

SILVA, M.F.F. da; ROSA, N.A. 1989. Análise do estrato arbóreo da vegetação sobre jazida de cobre na Serra dos Carajás-Pa. Bol. Mus. Para. Emilio Goeldi. Sér. Botânica. Vol. 5(2): 175-206.

SILVA. M.F.F. da: ROSA. N.A. 1990. Estudos Botânicos na Área do Projeto Ferro Carajás. Serra Norte. I - Aspectos ecológicos e vegetacionais dos campos rupestres (1). Anais XXXV Congresso Nacional de Botânica, Manaus-Am, 1984. : 367-379. Brasília - IBAMA.

TAKEUCHI, M. 1960). The Structure of the Amazonian vegetation. I. Savana in Northern Amazon. Joum. Fac. Sci. Univ. Tokyo, Section III, Bot., 7(12):523-533. il.

VELOSO. H.P. 1974. Vegetação. Projeto Radam. Folha SC.22 - Tocantins. Rio de Janeiro. 4: 26-29. 
WILD, H. 1968/1969. Geobotanical anomalies in Rhodesia. I - The Vegetation of copper bearing soils. Kirkia, 7:1-71.
WILD, H.; BRADSHAW, A.D. 1977. The Evolutionary effects of metaliferous and other anomalous soils in South Central Africa. Evolution, 31:282-293. 